\title{
MODEL POETRY WORDGAMES DALAM PEMBELAJARAN EKSPRESI TULIS PUISI PADA PEMBELAJAR BAHASA INDONESIA BAGI PENUTUR ASING
}

\author{
Suci Sundusiah, Rosita Rahma \\ Universitas Pendidikan Indonesia \\ surel : suci_upi@yahoo.com
}

\begin{abstract}
ABSTRAK
Kegiatan ekspresi tulis puisi dalam pembelajaran BIPA (Bahasa Indonesia bagi Penutur Asing) dapat menjadi salah satu kegiatan yang meningkatkan penguasaan bahasa pembelajar. Karenanya, dibutuhkan kreatifitas dan variasi pembelajaran dalam menanganinya. Secara umum, penelitian ini bertujuan untuk menemukan profil kemmapuan ekspresi tulis artistik pembelajar BIPA. Untuk memudahkan penemuan penelitian, peneliti memilih model poetry wordgames sebagai strategi pembelajaran. Secara khusus, penelitian ini bertujuan untuk mengetahui: (1) bagaimana profil kemampuan ekspresi tulis puisi pembelajar BIPA program Kerja sama UPI-Youngsan University sebelum diberikan treatment ? (2) Bagaimana proses treatment pembelajaran ekspresi tulis puisi dengan menggunakan model poetry wordgames pada pembelajar BIPA program Kerja sama UPI-Youngsan University? Bagaimana profil kemampuan ekspresi tulis puisi pembelajar BIPA program Kerja sama UPI-Youngsan University setelah diberikan treatment?. Penelitian ini menggunakan metode subjek tunggal sebagai pisau analisis. Dengan desain penelitian two base line period. Hasil penelitian menunjukkan bahwa (1) pembelajar telah memiliki pola pemahaman yang baik mengenai puisi sebelum diberi tindakan hanya saja mereka tidak terbiasa menulis puisi, sehingga perlu dilakukan latihan dan pengenalan terhadap model-model puisi Indonesia; (2) model Poetry Wordgames sangat tepat untuk melatih pembelajar dalam pemilihan kosa kata (diksi) puisi, ketika model ini dipadukan dengan teknik lain maka hasil pembelajaran lebih optimal; (3) pembelajar telah mampu menuangkan ide, imajinasi, pengalaman dan emosi mereka ke dalam puisi melalui beragam bentuk majas atau gaya bahasa di antaranya: metafora, perumpamaan (asosiasi), perbandingan, hiperbola, repetisi, paralelisme, dan personifikasi.
\end{abstract}

Kata Kunci: model Poerty Wordgames, pembelajar BIPA, gaya bahasa atau majas.

\section{ABSTRACT}

The activity of writing a poem in the learning of BIPA (Bahasa Indonesia bagi Penutur Asing) is able to be one of activity which increases the mastering of learner language. Because it is need the creativity and learning variation in handling it. Generally, the research aims to find out the ability profile of artistic writing expression of BIPA learner. To make easy the research finding, researcher chooses the model of poetry word games as a learning strategy. Especially, the research purposes for: (1) how is the ability profile of poem writing expression of BIPA learning on cooperation program among UPI with Youngsan University before given a treatment? (2) how is the treatment process of poem writing expression of BIPA learning on cooperation program among UPI with Youngsan University after given a treatment? The research used one and only subject method as analysis knife by research design two base line period. The result of research shows that (1) the learner had a good comprehension model about a poem before given an action, but they are not accustomed to write a poem, so it is need to do a training and introduction through the model of Indonesia poem; (2) the model of Poetry Word games is very exact to train the learner in selecting the vocabularies (diction) poem, when this model compacts with other technique so the result of learning is more optimal; (3) the learner had able to state the idea, imagination, experience and their emotional into a poem through various form of figures of speech, language style among: metafora, association, comparison, hyperbola, repetition, parallelism, and personification.

Keywords: model of Poerty Wordgames, BIPA learner, language style or figures of speech.

\section{PENDAHULUAN}

Belajar B2, sering dilekatkan dengan belajar tentang bahasa, seperti struktur gramatikal. Karenanya, kegiatan pembelajaran berkisar pada kegiatan menyampaikan informasi struktur bahasa. Padahal, terdapat prinsip pembelajaran B2, yakni "bahasa adalah seperangkat kebiasaan, jadi ajarkan bahasa bukan tentang bahasa". Prinsip ini sangat jelas memberikan arah dalam langkah pembelajaran B2. Bahwa pembelajar seharusnya belajar mengenai bagaimana berbahasa itu sendiri atau praktik berbahasa, bukan mempelajari tata bahasa semata. 
Berdasarkan prinsip tadi, muncul pemahaman bahwa belajar bahasa dapat dimasuki melalui berbagai aspek keterampilan berbahasa, termasuk aspek keterampilan bersastra. Melalui kegiatan bersastra seyogianya seseorang sedang belajar berbahasa. Melalui pintu puisi sebetulnya, pembelajar sedang mempelajari tata kalimat dan tata kata. Penelitian ini akan mengupayakan salah satu alternatif pembelajaran B2 dengan salah satu strategi pembelajaran sastra. Strategi ini diturunkan dalam bentuk model Poetry Wordgames yang sudah dikenal sejak tahun 1993. Strategi ini diharapkan mampu menjembatani kesulitan bahasa pengantar mengingat $\mathrm{B} 1$ pembelajar tidak dikuasai pengajar.

Penelitian ini bertujuan untuk mengetahui dan menganalisis profil kemampuan ekspresi tulis puisi pembelajar BIPA program Kerja sama UPI-Youngsan University sebelum dan setelah diberikan treatment model poetry wordgames, serta mendeskripsikan penerapan model tersebut dalam pembelajaran.

\section{Pembelajaran Ekspresi Tulis Puisi}

Permasalahan apa itu puisi masih banyak diperdebatkan definisinya. Mengapa? Karena puisi modern memiliki bentuk dan tipografi yang semakin beragam. Puisi tidak hanya terdiri atas kata-kata yang dirangkai dalam bentuk baris, kelompok kalimat yang menyerupai cerita pendek sekali pun kini dikategorikan puisi; kumpulan titik dan tanda baca kini menjadi puisi. Karenanya, para kritikus sastra semakin memperluas hakikat puisi itu sendiri, tidak hanya sebagai kelompok kata yang dirangkai dalam sekelompok baris dan bait yang beraturan, tetapi lebih pada konsep kata puitis yang disampaikan.

Pengertian puisi yang disampaikan Waluyo ini misalnya, mengacu pada teks sastra berjenis puisi yang masih umum, yakni puisi adalah bentuk karya sastra yang mengungkapkan pikiran dan perasaan penyair secara imajinatif. Karenanya, beliau menambahkan kriteria struktur puisi agar konsep puisi menjadi lebih terarah, yakni proses penyusunan puisi itu harus mengonsentrasikan struktur fisik dan struktur batinnya (Waluyo,2002:25).

Namundemikian, perludipertegas keberadaan puisi sebagai salah satu genre sastra yang menurut Luxemburg (1978:175) dapat dibedakan berdasarkan situasi bahasanya. Situasi bahasa puisi bersifat monolog, artinya hanya terjadi komunikasi satu arah antara penyair dan pembaca atau audien. Monolog puisi dapat bersifat aku lirik atau naratif. Menurut Siswanto, akulirik dapat bermacammacam bentuknya, pada puisi Rendra Sajak Anak Muda aku lirik adalah "kita". Dalam puisi Chairil Anwar aku lirik adalah "beta Pattirajawane". Dengan kata lain, aku lirik biasanya dinyatakan dengan bentuk persona "aku, kita, kami, beta, hamba, saya,ku" (Siswanto, 2013:99).

Menurut Siswanto, bentuk dan struktur puisi mencakup : (1) perwajahan puisi, (2) diksi, (3) pengimajian, (4) kata konkret, (5) majas atau bahasa figuratif, dan verifikasi (2013:102). Sementara itu L.A Richard dalam Siswanto (2013,112-114) menyatakan bahwa struktur batin puisi merupakan hakikat puisi. Struktur batin puisi itu meliputi (1) tema atau makna (sense), (2) rasa (feeling), (3) nada (tone), dan (4) amanat; tujuan; maksud (intention). Makna berkaitan dengan makna bahasa (semantik).

Pembelajaran bersastra di kelas, terbagi ke dalam dua kegiatan utama, yakni kegiatan apresiasi dan kegiatan ekspresi sastra. Kegiatan apresiasi sastra merupakan kegiatan artistik terhadap karya sastra. Kegiatan ini dijelaskan oleh Effendi (2002) sebagai kegiatan menggauli karya sastra secara sungguh-sungguh sehingga tumbuh pengertian, penghargaan, pikiran kritis, dan kepekaan perasaan yang baik terhadap karya sastra. Kegiatan apresiasi sastra dapat diwakili dengan kegiatan membaca karya sastra, menonton sebuah pentas sastra, atau sekadar menyimak pembacaan karya sastra.

Sementara itu, kegiatan ekspresi sastra merupakan kegiatan estetik terhadap 
karya sastra. Dengan kata lain, seseorang yang telah memiliki pengalaman apresiasi terhadap karya sastra maka ia kemudian berusaha untuk memproduksi karya sastra. Karya sastra yang ditulisnya didasarkan pada pengalaman apresiasi terhadap karya sastra sebelumnya. Kegiatan ekspresi sastra ada yang berbentuk lisan, ada pula yang berbentuk tulisan. Ekspresi lisan dapat berupa deklamasi atau pembacaan karya sastra. Misalnya pembacaan puisi atau Cerpen. Sementara ekspresi tulis dapat berupa menghasilkan teks puisi.

Kegiatan ekspresi tulis puisi dianggap sebagai salah satu kegiatan tersulit dalam bersastra. Kegiatan ini membutuhkan kepekaan batin dan keluwesan dalam menghasilkan kalimat atau kata-kata puitis yang terpilih. Kegiatan ini membutuhkan perenungan dan waktu yang cukup lama dalam menghasilkan karya sastra, terutama bagi penulis pemula. Kegiatan menulis puisi membutuhkan kreativitas memilih kata-kata yang tepat.

\section{Model Pembelajaran Poetry Wordgames}

Dianne Bates (1993) menyampaikan pertama kali model pembelajaran yang menitikberatkan pada konsep belajar bahasa dengan "menyenangkan" ini. Menurut Bates, pembelajaran bahasa harus dibuat menyenangkan dan dapat dilakukan oleh pengajar mana pun. Pembelajaran menulis puisi dengan metode ini dapat dilakukan secara berkelompok di kelas, perseorangan (mandiri), atau untuk tujuan kompetetif sehingga dapat memacu kompetensi pembelajar dalam memproduksi kata.

Model Poetry Wordgames dapat dilakukan secara berkelompok di dalam kelas, sehingga dapat memacu kemampuan kepemimpinan pembelajar. Masing-masing pembelajar berkontribusi menyumbangkan kata dan ide puisi, sehingga puisi utuh menjadi milik bersama. Dalam penelitian ini, kompetensi yang akan dibidik adalah kompetensi individu pembelajar, sehingga kegiatan menulis puisi dilakukan secara mandiri.

Model Poetry Wordgames akan mengajarkan kepada pembelajar keberadaan rima dan repitisi dalam puisi. Pembelajar akan ditantang untuk memilih kata yang memiliki rima sesuai dengan kata sebelumnya, tentu kata tersebut juga harus memiliki kaitan makna dengan kata sebelumnya. Dengan demikian pembelajar akan memahami bahwa puisi yang mereka tulis memiliki efek bunyi yang mempengaruhi makna.

\section{Pembelajaran Ekspresi Sastra di Kelas BIPA}

Penjelasan bahwa menulis puisi merupakan kegiatan yang cukup rumit, nampaknya sedikit tidak sesuai dengan kriteria pembelajar BIPA. Namun, demikian konteks ekspresi tulis puisi di sini lebih menitikberatkan pada tujuan bahwa dengan melalui puisi, pembelajar BIPA dapat meningkatkan kompetensi berbahasa Indonesia mereka.

Karena adanya kerumitan dalam hal proses menulis puisi maka dibutuhkan upaya pengondisian batin dan mental para pembelajar. Kesiapan kosa kata mereka, tentu tidak cukup membantu, perlu kesiapan batin sebelum mengeluarkan kata-kata mereka. Proses ini perlu rangsangan dan strategi terntu dari pengajar agar memudahkan pembelajar dalam mengekspresikan kata-kata puitisnya.

Di kelas BIPA proses menulis puisi perlu pembimbingan yang maksimal. Dalam menentukan pilihan kata misalnya, pengajar perlu memberikan arahan, kelaziman kata yang sering digunakan pada puisi Indonesia. Kata-kata baku seperti "Anda" "Saudara" yang mereka ketahui sebagai kata ganti dalam lingkungan formal, perlu dieliminasi mengingat bahasa puisi tidak bersifat formal. Pengajar bisa melakukan pemodelan terlebih dahulu, misalnya memberikan contoh puisi Indonesia yang memiliki unsur-unsur puisi yang cukup lengkap. Lalu menjelaskan unsur-unsur tersebut secara mudah.

Karena faktor kerumitan tadi, maka puisi di kelas BIPA seyogianya disampaikan pada pembelajar tingkat mahir. Sebagaimana yang tertera dalam CEF (Common European Framework ) bahwa pada tingkat $\mathrm{C} 1$ 
(proficient user) atau tingkat mahir awal, pembelajar bahasa bagi penutur asing memiliki indikator kemahiran sebagai berikut:

a) Can understand a wide range of demanding, longer texts, and recognize implicit meaning.

b) Can express him/herself fluently and spontaneously without much obvious searching for expressions.

c) Can use language flexibly and effectively for social, academic and professional purposes.

d) Can produce clear, wellstructured, detailed text on complex subjects, showing controlled use of organizational patterns, connectors and cohesive devices.

(Common Reference Global Level, A Teacher's Guide To Common

European Framework, 2001)

Berdasarkan kompetensi berbahasa versi CEF di atas, maka pembelajaran menulis puisi akan dengan mudah disampaikan pada pembelajar dengan kompetensi tersebut.

\section{METODE PENELITIAN}

Penelitian menggunakan pendekatan eksperimental dengan metode single-subjek design. Pemilihan metode ini karena hanya ada satu subjek tunggal penelitian. Agar mencapai tujuan penelitian, maka teknik yang dipilih adalah model A-B-A dengan format A-B-A Design - Two Baseline Periods with One Treatment Period.

Subjek penelitian ini adalah 13 orang mahasiswa asal Korea Selatan yang sedang mengikuti program belajar bahasa Indonesia di Jurusan Pendidikan Bahasa dan Sastra Indonesia yang bekerja sama dengan P3BIPA (Pusat Pengkajian dan Pengajaran BIPA) FPBS UPI. Mahasiswa iniberasal dari kampus Youngsan University yang di universitas asal mereka, mereka telah mengikuti program belajar bahasa Indonesia. Dengan kategori tersebut mereka dapat dikategorikan sebagai pembelajar bahasa tingkat mahir menurut CEF dan dapat dikembangkan kompetensi berbahasa Indonesia mereka melalui puisi.

\section{HASIL PENELITIAN}

Data pada BL1 (Base Line 1) menunjukkan bahwa pembelajar sebetulnya telah memiliki konsep mengenai puisi sebagaimana puisi pada umumnya, hanya saja mereka belum terbiasa menulis puisi. Kasus pada Edi dan Chandra yang memiliki bakat dalam seni berbahasa ternyata dapat berkembang pesat setelah melalui pembelajaran. Data pada T1 (Treatment 1) menunjukkan bahwa kegiatan pembelajaran dengan teknik poetry wordgames ternyata mampumemperkenalkan kepada pembelajar bagaimana mengelola diksi dalam puisi. Pembelajar belajar bagaimana menentukan kosa kata yang tepat untuk mewakili imajinasinya. Data pada T2 (treatment 2) menunjukkan bahwa kegiatan pembelajaran dengan model Poetry Wordgames yang dikombinasikan dengan teknik sugestopedia mampu menstimulus imajinasi pembelajar dalam menentukan diksi pada puisinya. Selain itu, teknik ini membawa pembelajar pada suasana ekspresi emosi dengan baik.

Data pada BL2 (Base Line 2) menunjukkan bahwa kegiatan menulis puisi dalam tempo penulisan terbatas membuat pembelajar tidak dapat berekspresi dengan baik. Puisi perlu pendalaman emosi sehingga pembelajar akan dengan mudah menuangkan ideide mereka. Data pada BL3 (Base Line 3) menunjukkan hasil yang lebih baik daripada BL2. Pembelajar dengan baik mampu mengekspresikan diri dan emosinya ke dalam puisi melalui media bunga.

Pembelajar telah mampu mengekspresikan diri ke dalam puisi melalui beragam gaya bahasa, yaitu: (1) perumpamaan, (2) metafora, (3) personifikasi, (4) repetisi, (5) pertentangan, (6) paradoks, (7) paralelisme, 
(8) hiperbola, (9) sinekdok-pars prototo, (10) elipsis, dan (11) citraan gerak. Pembelajar telah mampu menciptakan frasa-frasa atau klausa segar (tidak klise) seperti yang ditulis oleh Edi kain langit,daun indah, mawar menghabiskan kecantikannya; ditulis Tito seratus mawar adalah cinta; ditulis Chandra nama itu bebas terbang ke hati kita; ditulis Amel hati mencelup beraneka warna dan karya Sandi niscaya dalam ingatan, kaktus lapar cinta.

\section{KESIMPULAN}

Kegiatan pembelajaran BIPA dapat dilakukan melalui pintu apresiasi dan ekspresi sastra. Model Poetry Wordgames ternyata mampu memperkenalkan pembelajar pada konsep diksi yang dipilih secara apik saat menulis puisi. Menulis puisi yang merupakan kegiatan khusus, perlu penanganan yang serius, ternyata dilakukan oleh siapa saja, termasuk oleh pembelajar bahasa kedua. Puisi akan lebih mengasyikan jika dilakukan dengan menstimulus pembelajar dengan beragam metode atau teknik pembelajaran di kelas. Puisi mampu mengembangkan diri pembelajar untuk lebih apresiatif terhadap perasaan dan pengalaman mereka; meningkatkan kepekaan pembelajar dalam bersikap dan memunculkan semangat mereka untuk menulis lebih baik. Dengan demikian, pembelajaran BIPA tidak selalu harus mengajarkan bahasa melalui pintu gramatika bahasa, tetapi juga dapat dimasuki melalui kegiatan bersastra.

\section{DAFTAR PUSTAKA}

Bates, Dianne. (1993). Wordgames: Activities for Creative Thinking and Writing. USA : Longman.

CEF Team. (2001). A Teacher's Guide To The Common European Framework. London : Longman.

Damono, Sapardi. (1994). Hujan Bulan Juni (Kumpulan Puisi). Jakarta : Grasindo.

Effendi. ( 2002). Bimbingan Apresiasi Puisi. Jakarta : Pustaka Jaya.
Fraenkel, Jack R. dan Norman E. Wallen. (1993). How To Design and Evaluate Research in Education. Singapore : Mc Graw-Hill.

Luxemburg, Jan Van, Mieke Bal dan Westjein G. (1984). Pengantar Ilmu Sastra. Jakarta : Gramedia.

Siswanto, Wahyudi. (2013). Pengantar Teori Sastra. Yogyakarta : AM Publishing.

Waluyo, Herman J. (2002). Apresiasi Puisi. Jakarta : Gramedia Pustaka Utama. 